DOI: $10.24850 / j-t y c a-2021-01-07$

Artículos

\title{
Aplicación de bioensayos ecotoxicológicos para evaluar la calidad del agua del arroyo Cañuelas (Buenos Aires, Argentina)
}

\section{Application of ecotoxicological bioassays to assess the water quality in the Cañuelas stream (Buenos Aires, Argentina)}

Verónica Sykora ${ }^{1}$ ORCID: https://orcid.org/ 0000-0001-5537-6273

Araceli Clavijo2, ORCID: https://orcid.org/0000-0001-8370-6073

Daniel Calvo ${ }^{3}$

M. Florencia Kronberg4, ORCID: https://orcid.org/0000-0002-7070-3604

Samuel Díaz ${ }^{5}$

Carlos Gómez 6

Eliana Munarriz7, ORCID: https://orcid.org/0000-0002-3556-117X

Ariana Rossen ${ }^{8}$, ORCID: https://orcid.org/0000-0002-5342-3360

${ }^{1}$ Laboratorio Experimental de Tecnologías Sustentables, Centro del Uso del Agua, Instituto Nacional del Agua, Buenos Aires, Argentina, vero_sykora@hotmail.com 
2Instituto de Investigaciones en Biociencias Agrícolas y Ambientales, CONICET-Universidad de Buenos Aires, Buenos Aires, Argentina, a.clavijo@agro.uba.ar

${ }^{3}$ Dirección de Servicios Hidrológicos, Instituto Nacional del Agua, Buenos Aires, Argentina, dcalvo@ina.gob.ar

${ }^{4}$ Instituto de Investigaciones en Biociencias Agrícolas y Ambientales, CONICET-Universidad de Buenos Aires, Buenos Aires, Argentina, kronberg@agro.uba.ar

${ }^{5}$ Laboratorio Experimental de Tecnologías Sustentables, Centro del Uso del Agua, Instituto Nacional del Agua, Buenos Aires, Argentina, ndiaz@ina.gob.ar

6Laboratorio Experimental de Tecnologías Sustentables, Centro del Uso del Agua, Instituto Nacional del Agua, Buenos Aires, Argentina, egomez@ina.gob.ar

7Instituto de Investigaciones en Biociencias Agrícolas y Ambientales, CONICET-Universidad de Buenos Aires, Buenos Aires, Argentina, eliana.munarriz@gmail.com

8Laboratorio Experimental de Tecnologías Sustentables, Centro del Uso del Agua, Instituto Nacional del Agua, Buenos Aires, Argentina, arossen@ina.gob.ar

Autora para correspondencia: Ariana Rossen, arossen@ina.gob.ar 


\section{Resumen}

La inclusión de los análisis ecotoxicológicos en los estudios ambientales resulta indispensable, pues aporta información sobre los efectos que los contaminantes puedan causar en los organismos expuestos y en los ecosistemas receptores. El objetivo del trabajo fue evaluar la calidad del agua en la cuenca del arroyo Cañuelas (Buenos Aires, Argentina), a partir de determinaciones fisicoquímicas y de bioensayos ecotoxicológicos estandarizados en diferentes niveles tróficos con los organismos: Pseudokirchneriella subcapitata, Lactuca sativa y Caenorhabditis elegans. Las muestras se extrajeron de cuatro puntos de muestreo representativos a lo largo del cauce de los arroyos Cañuelas y Navarrete. P. subcapitata y la raíz de $L$. sativa presentaron los valores más altos de inhibición del crecimiento en los puntos de muestreo coincidentes con un mayor deterioro de la calidad del agua de acuerdo con los niveles propuestos por la normativa local. Por el contrario, C. elegans reveló toxicidad en muestras cuyos parámetros fisicoquímicos cumplieron con la normativa vigente. Los resultados de este trabajo respaldan la necesidad de incorporar una batería de bioensayos ecotoxicológicos que complementen los análisis fisicoquímicos y contribuyan a una mejor gestión de los recursos hídricos.

Palabras clave: parámetros fisicoquímicos, toxicidad aguda, ecotoxicidad, cuenca hídrica, contaminación, efluentes industriales.

\section{Abstract}


The inclusion of ecotoxicological analyzes in environmental studies is essential as it provides information on the effects that pollutants may have on exposed organisms and on receiving ecosystems. The aim of the work was to evaluate the water quality in the Cañuelas stream basin (Buenos Aires, Argentina) from physicochemical determinations and ecotoxicological bioassays with standardized organisms of different trophic levels: Pseudokirchneriella subcapitata, Lactuca sativa and Caenorhabditis elegans. Samples were taken from four representative sampling points along the Cañuelas and Navarrete streams. $P$. subcapitata and the root of L. sativa had the highest growth inhibition values at the sampling points that coincided with a greater deterioration of water quality and according to the levels proposed by local regulations. In contrast, $C$. elegans revealed toxicity in samples whose physicochemical parameters complied with current regulations. The results of this work support the need to incorporate a battery of ecotoxicological bioassays that complement the physicochemical analysis and contribute to a better management of water resources.

Keywords: Physicochemical parameters, acute toxicity, ecotoxicity, hydric basin, pollution, industrial sewage.

Recibido: 01/08/2019

Aceptado: $28 / 05 / 2020$ 


\section{Introducción}

El deterioro progresivo de la calidad del agua a causa de la presencia de una multiplicidad de compuestos producto del arrastre superficial y de las continuas descargas directas e indirectas de efluentes domésticos, industriales y agrícolas, se ha convertido sin duda en uno de los motivos de mayor preocupación a nivel mundial (Barceló \& López, 2008; Iqbal, 2016). Dada esta problemática, las agencias de control ambiental han establecido diferentes metodologías para evaluar las características y grado del deterioro de los recursos hídricos, que incluyen el muestreo periódico de parámetros para determinar la calidad de agua (Strobl \& Robillard, 2008; Bakker \& Cook, 2011).

En Argentina, como en otros países de Latinoamérica, los estudios de calidad de agua determinan una serie de parámetros fisicoquímicos y bacteriológicos de acuerdo con los diferentes usos del agua establecidos por las normativas vigentes. Sin embargo, resulta imposible estimar los posibles efectos adversos que esas muestras ambientales pueden causar en los organismos y ecosistemas expuestos, dada la complejidad que representa, por un lado, cuantificar la totalidad de los compuestos presentes, así como evaluar los múltiples efectos de esas mezclas complejas sobre los organismos. Por tanto, el enfoque tradicional, 
centrado en parámetros fisicoquímicos y bacteriológicos, sólo permite prever parcialmente los posibles efectos adversos en aquellas muestras en las que se conocen y se han cuantificado los compuestos tóxicos, y cómo esa toxicidad puede estar modulada por otros parámetros fisicoquímicos, tales como $\mathrm{pH}$, salinidad, etcétera, que también se determinan en el mismo análisis ambiental (Kim, Jun, Jo, Shim, \& Jung, 2008; Ferrari, 2015).

Por este motivo, resulta necesario incorporar otras herramientas en los análisis de calidad ambiental, como la evaluación de las características toxicológicas. Con este fin se han estandarizado bioensayos que emplean diversos organismos pertenecientes a diferentes niveles tróficos y que presentan una respuesta biológica cuantificable ante la exposición a contaminantes (Castillo-Morales, 2004; Arias et al., 2016).

Las respuestas evaluadas en los bioensayos pueden ser agudas o crónicas y cubren un amplio rango de niveles de organización biológica, desde el nivel molecular y bioquímico hasta el conductual o fisiológico (Ferrari, 2015). Para que un bioensayo sea considerado óptimo debe cumplir con diferentes características, siendo las más importantes su reproducibilidad, sensibilidad y bajo costo (Boudou \& Ribeyre, 1997).

Diversas instituciones y gobiernos alrededor del mundo han avalado y promovido el uso de los bioensayos ecotoxicológicos para el análisis de sus cuerpos de aguas superficiales (Castillo-Morales, 2004; MendozaCantú, Ramírez-Romero, \& Pica-Granados, 2007; Teodorović, 2009; Maltby et al., 2010; Palma et al., 2010; Connon, Geist, \& Werner, 2012). 
Para determinar los efectos fitotóxicos de muestras ambientales o sustancias puras, las algas verdes han sido ampliamente utilizadas como modelos biológicos debido a que cumplen un rol crítico en los ecosistemas acuáticos tanto por ser un componente esencial de la red trófica como por su participación en los ciclos biogeoquímicos (Franklin, Stauber, \& Lim, 2001; Stevenson, 2014). En particular, Pseudokirchneriella subcapitata debido a su alta sensibilidad, estabilidad genética y fácil cultivo, además de su amplia distribución en diferentes regiones en el mundo, es una de las especies algales más utilizada en bioensayos ecotoxicológicos con validación internacional (Moreira-Santos, Soares, \& Ribeiro, 2004; Bohórquez-Echeverry \& Campos-Pinilla, 2007; OECD 2011; Environment Canada, 2007; EPA, 2002).

Otro grupo de productores primarios utilizados para los bioensayos ecotoxicológicos son las plantas vasculares (Maltby et al., 2010; Mkandawire, Teixeira-da-Silva, \& Dudel, 2014). Dentro de este grupo destaca la especie Lactuca sativa, cuya respuesta toxicológica puede ser evaluada durante la germinación y primeros días de desarrollo (GonzálezPérez, Marcos-Albear, Pérez-Garrido, Marín-Sánchez, \& Argota-Pérez, 2012; Rodríguez-Romero et al., 2014; Priac, Badot, \& Crini, 2017). Durante este periodo, la plántula se encuentra bajo una condición de alta sensibilidad frente a compuestos presentes en el medio de cultivo que pueden alterar numerosos procesos fisiológicos y, por tanto, la supervivencia y el desarrollo normal de ésta (Sobrero \& Ronco, 2004). Dado que estos procesos son comunes a muchas especies, el ensayo con semillas de lechuga es representativo para la evaluación de los efectos 
adversos de diferentes compuestos y condiciones ambientales en esta etapa de la planta.

Como modelos animales, se han propuesto una gran variedad de especies para predecir la respuesta biológica, cada una atendiendo diferentes niveles de relevancia ecológica (invertebrados, vertebrados). Entre ellos se destaca al nematodo Caenorhabditis elegans, organismo cosmopolita saprófito de vida libre que habita en el agua intersticial de las partículas del suelo, el cual está cobrando validez en virtud de su versatilidad para la evaluación de diferentes matrices ambientales (Hitchcock, Black, \& Williams, 1997; Höss et al., 2012; Höss et al., 2013; Clavijo et al., 2016). Su aceptación como modelo se fundamenta principalmente en la simplicidad de su sistema nervioso y la posibilidad de ser manipulado con facilidad, mostrando una gran tolerancia a las condiciones del medio, como pH, salinidad y dureza del agua (Khanna, Cressman, Tatara, \& Williams, 1997; Höss et al., 2012). El uso de C. elegans permite hacer experimentos de manera más fácil y menos costosa que en otros modelos animales y ofrece la posibilidad de estudiar en detalle mecanismos biológicos con alta reproducibilidad en los resultados (Fire, 2007). Su genoma ha sido totalmente secuenciado y bien caracterizado; además, sus respuestas tóxicas son comparables con las de animales superiores, pero sin los problemas éticos asociados con el trabajo con ellos (Leung et al., 2008; Doke \& Dhawale, 2015).

En este estudio se evaluó la calidad del agua del arroyo Cañuelas (A. Cañuelas) y uno de sus afluentes, el arroyo Navarrete (A. Navarrete), ambos localizados en la provincia de Buenos Aires, Argentina. Estos 
cauces de agua se encuentran en la parte alta de la Cuenca Matanza Riachuelo, la cual se extiende por un territorio aproximado de 2200 km² y ha sido considerada como una de las cuencas más contaminadas de Argentina (Berros, 2012; Faggi \& Breuste, 2014). Históricamente, la actividad principal en la subcuenca del $A$. Cañuelas fue agrícola-ganadera, mientras que en las últimas décadas se ha registrado un aumento poblacional y el establecimiento de diversas industrias (Gonzál ez, 2012). En consecuencia, ha habido un incremento en los vertidos de efluentes industriales y descargas domésticas que han contribuido a la degradación de los cauces de agua (Casal, 2004; Berros, 2012). Cabe destacarque en algunas zonas de esta subcuenca con menor impacto antrópico aún se mantiene un buen estado de conservación de la biodiversidad (Faggi \& Breuste, 2014).

Dada la situación de deterioro ambiental de la cuenca, en el año 2006 fue creada la Autoridad de Cuenca Matanza Riachuelo (ACUMAR), como ente autónomo, autárquico e interjurisdiccional, cuya responsabilidad primaria es implementarun plan de saneamiento de dicha cuenca. En este contexto, se establecieron objetivos de calidad según diferentes usos (Resolución No 46/2017; ACUMAR, 2017) de implementación progresiva. ACUMAR tiene establecido como objetivo de calidad de agua el "Uso IV-Agua apta para actividades recreativas pasivas", constituyéndose como una meta mínima de calidad.

En el marco descrito, este estudio evalúa la respuesta ecotoxicológica de $P$. subcapitata, $L$. sativa y $C$. elegans por exposición a muestras de agua provenientes de la subcuenca del A. Cañuelas, con el 
fin de aportar un análisis del nivel de impacto toxicológico, así como generar antecedentes para la posible implementación de estas herramientas en los planes futuros de gestión de la cuenca.

\section{Materiales y métodos}

\section{Área de estudio}

El arroyo Cañuelas está en la provincia de Buenos Aires, Argentina, en el partido homónimo. Este arroyo es tributario del río Matanza Riachuelo; posee un caudal medio de $1.52 \mathrm{~m}^{3} \mathrm{~s}^{-1}$ y su cuenca cubre una superficie de $368.311 \mathrm{~km}^{2}$. Para su estudio, se establecieron cuatro puntos de muestreo de agua superficial. El punto AC1 (S 35० 1' 23"; W $58^{\circ} 40^{\prime} 43^{\prime \prime}$ ) es el más cercano a la naciente del arroyo; posee un caudal medio de $0.17 \mathrm{~m}^{3} \mathrm{~s}^{-1}$, y se emplaza en una zona de uso agrícola-ganadero con industrias mayormente dedicadas al procesamiento de productos cárnicos y sus subproductos (ACUMAR, 2016). El punto AC2 (S 34 58' 5"; W $58^{\circ}$ $39^{\prime} 24^{\prime \prime}$ ), ubicado $6.6 \mathrm{~km}$ río abajo del punto $\mathrm{AC1}$, localiza en un área 
periurbana, con pequeños barrios residenciales. El punto AN (S 34 $55^{\prime}$ 30"; W $58^{\circ} 36^{\prime} 37^{\prime \prime}$ ) se localiza sobre el arroyo Navarrete, que posee un caudal medio de $0.39 \mathrm{~m}^{3} \mathrm{~s}^{-1}$ y confluye con el $\mathrm{A}$. Cañuelas a $6.7 \mathrm{~km}$ río abajo del punto AC2. En las cercanías de este arroyo se localizan urbanizaciones que en algunas zonas carecen de servicios sanitarios, además de barrios residenciales privados y pequeñas industrias dispersas que descargan efluentes al arroyo. Finalmente, el punto AC3 (S 34 54' $54^{\prime \prime} ;$ W $58^{\circ} 37^{\prime} 56^{\prime \prime}$ ) se encuentra en un área residencial a $1.5 \mathrm{~km}$ río abajo del punto de confluencia de ambos arroyos, en donde alcanza un caudal promedio de $1.52 \mathrm{~m}^{3} \mathrm{~s}^{-1}$ (ACUMAR, 2018). La Figura 1 ilustra la posición de los puntos de muestreo en el área de estudio dentro de la subcuenca del A. Cañuelas. 

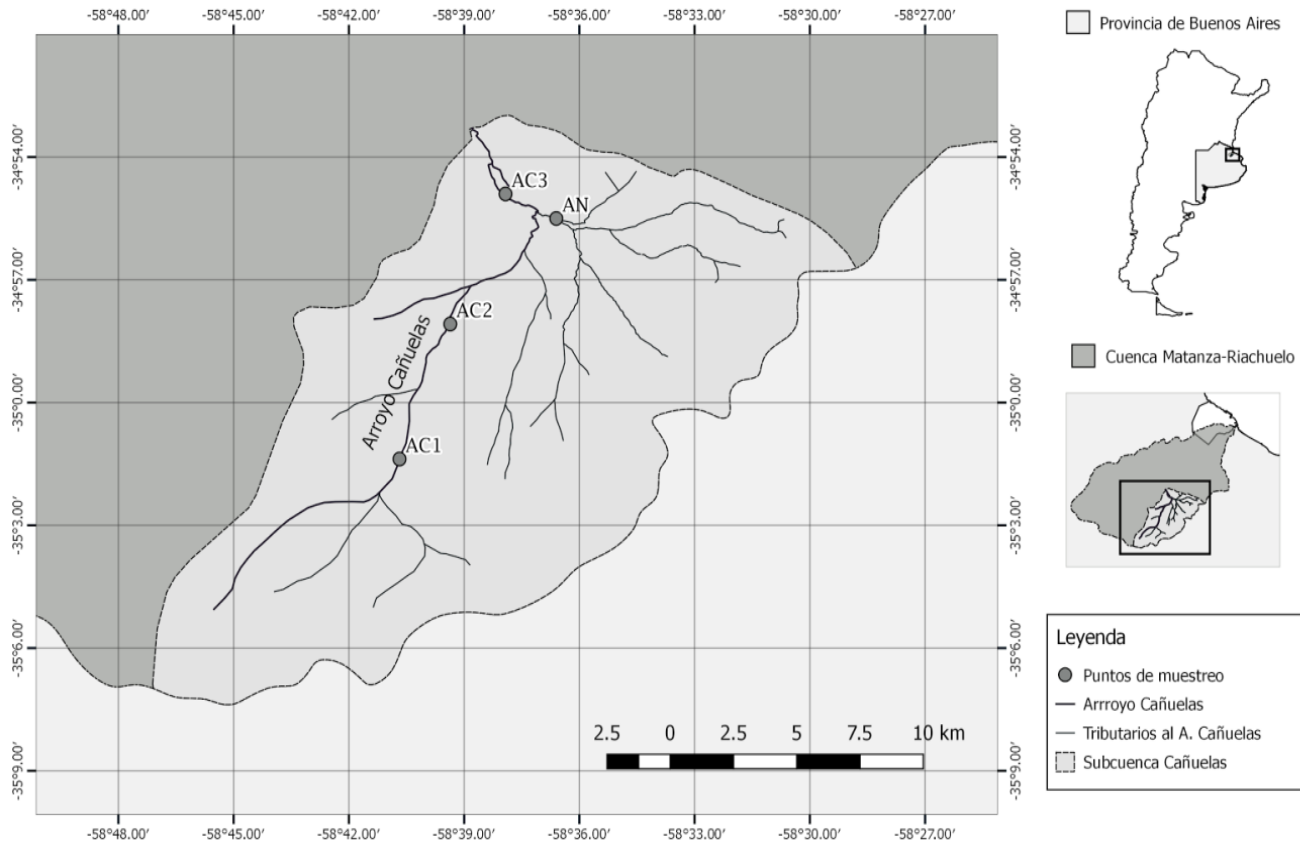

Leyenda

O Puntos de muestreo

- Arrroyo Cañuelas

- Tributarios al A. Cañuelas

[-] Subcuenca Cañuelas

Figura 1. Área de estudio y ubicación de los puntos de muestreo en la cuenca del A. Cañuelas.

La recolección de las muestras de agua se realizó en los meses de noviembre y diciembre de 2015, y febrero de 2016. En los cuatro puntos de muestreo ( $A C 1, A C 2, A C 3$ y $A N$ ) se accedió hasta la sección media del cauce usando un equipo wader. La extracción de las muestras fue a nivel subsuperficial (a $0.4 \mathrm{~m}$ ) y se utilizaron cuatro botellas por punto de muestreo. Para los parámetros fisicoquímicos se utilizaron tres botellas de $1 \mathrm{I}$, una de plástico y 2 de vidrio color ámbar. A estas últimas se les adicionó $0.5 \mathrm{ml}$ de una solución de $\mathrm{H}_{2} \mathrm{SO}_{4} 1: 1 \mathrm{v} / \mathrm{v}(\mathrm{pH}<2)$ para la preservación, según los requerimientos especificados de la determinación 
analítica. Por último, se utilizó un envase de plástico estéril de $250 \mathrm{ml}$ para los bioensayos ecotoxicológicos. Las botellas fueron distribuidas en conservadoras de $32 \mathrm{I}$, conteniendo hielo para mantener las muestras de agua a $4{ }^{\circ} \mathrm{C}$ hasta ser remitidas al laboratorio. El almacenamiento, transporte y preservación se llevó a cabo según metodología estandarizada (APHA, 2012). Se aclara que en el monitoreo del mes de noviembre de 2015, la toma de muestra del punto AC2 no se efectuó debido a dificultades en el acceso al punto de muestreo.

\section{Determinaciones de los parámetros fisicoquímicos}

La conductividad eléctrica ( $C E), \mathrm{pH}$ y oxígeno disuelto (OD) se determinaron in situ con el empleo de una sonda multiparamétrica HANNA modelo HI 9828. En laboratorio, a las muestras de agua recolectadas se les realizaron las siguientes mediciones: demanda biológica de oxígeno $\left(\mathrm{DBO}_{5}\right)$, demanda química de oxígeno (DQO), nitrógeno total de Kjeldahl (NTK) y fósforo total (PT), según la metodología propuesta por el

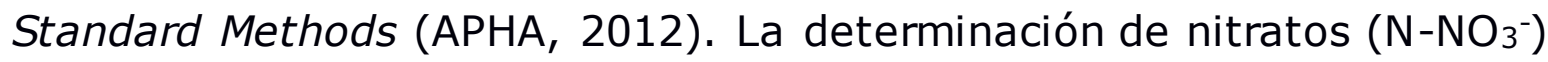
se hizo mediante el método 9200 de la Agencia de Protección Ambiental de los Estados Unidos-EPA (EPA, 1992). 
Asimismo, se determinó un índice de biodegradabilidad de la materia orgánica presente en las muestras a partir de la relación $\mathrm{DBO}_{5} / \mathrm{DQO}$. Este coeficiente da una medida aproximada de la proporción de materia aeróbicamente biodegradable respecto de los compuestos de carbono totales oxidables. La clasificación que se establece para este índice respecto de la biodegradabilidad de la materia orgánica es el siguiente: $\mathrm{DBO}_{5} / \mathrm{DQO}>0.5$, fácilmente biodegradable; $\mathrm{DBO}_{5} / \mathrm{DQO}=0.5$ - 0.25, moderadamente biodegradable; $\mathrm{DBO}_{5} / \mathrm{DQO}=0.25-0.1$, poco biodegradable, y $\mathrm{DBO}_{5} / \mathrm{DQO}<0.1$ no biodegradable (presencia de materia orgánica recalcitrante) (Samudro \& Mangkoedihardjo, 2010; Abdalla \& Hammam, 2014).

En todos los muestreos realizados se determinaron los ocho parámetros fisicoquímicos mencionados y se evaluaron los tres bioensayos ecotoxicológicos, excepto en el mes de noviembre, donde sólo se implementó el bioensayo con L. sativa y C. elegans. Como parte de la determinación analítica de los parámetros de DQO PT, NTK y N-NO${ }_{3}^{-}$, se evaluaron duplicados de cada muestra y se reportaron los valores promedio.

Las mediciones obtenidas de los parámetros $\mathrm{pH}, \mathrm{OD}_{1} \mathrm{DBO}_{5}, \mathrm{PT}$ y $\mathrm{N}$ $\mathrm{NO}_{3}^{-}$fueron contrastadas con los niveles guía de calidad de agua establecidos por la ACUMAR, vigentes al momento de la redacción de este trabajo y correspondientes al criterio de "Apta para Protección de la Biota" (ACUMAR, 2017) (Tabla 1). 
Tabla 1. Niveles Guía de la ACUMAR para protección de la biota.

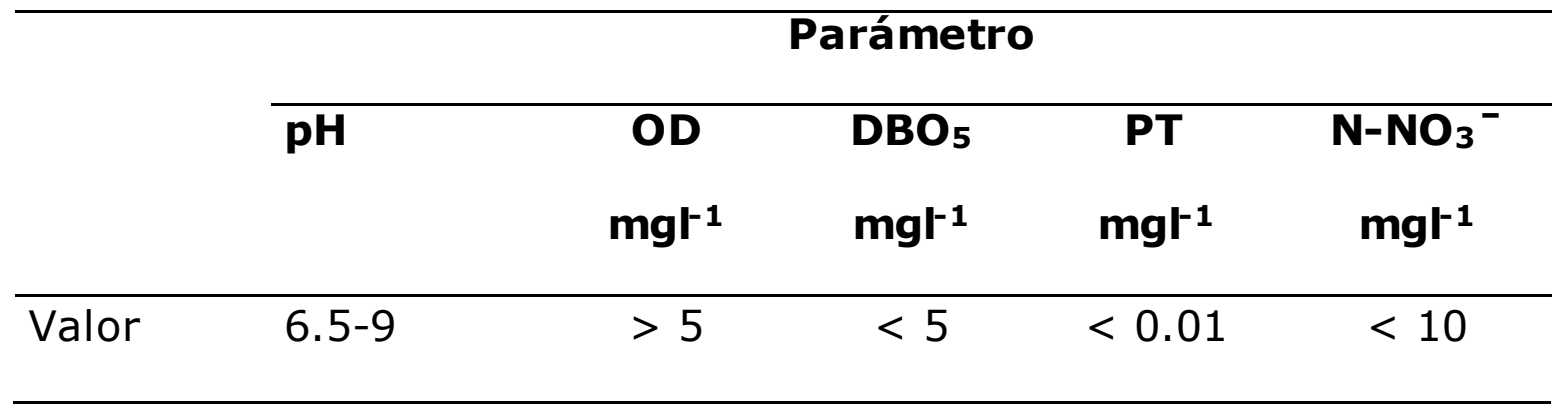

\section{Ensayos ecotoxicológicos}

Se realizaron los bioensayos ecotoxicológicos estandarizados con los siguientes organismos: Pseudokirchneriella subcapitata, Lactuca sativa y Caenorhabditis elegans.

\section{Pseudokirchneriella subcapitata}

El bioensayo de toxicidad aguda con $P$. subcapitata se realizó con base en el protocolo No 201 sugerido por la OECD (2011). Los cultivos de esta 
especie provienen del Culture Collection of Algae and Protozoa, Reino Unido (CCAP No 278/4). El bioensayo se realizó en viales de vidrio, conteniendo $6 \mathrm{ml}$ de muestra, adicionada con $0.3 \mathrm{ml}$ del medio de cultivo propuesto por OECD (2011) y una alícuota de un precultivo de algas de 5 \pm 2 días de crecimiento, con un inóculo de $2 \times 10^{5} \mathrm{celml}^{-1}$. Los viales fueron incubados durante $72 \mathrm{~h}$ a $24 \pm 2{ }^{\circ} \mathrm{C}$ bajo agitación continua a $48 \mathrm{rpm}$ e iluminación permanente con luz blanca $\left(25 \mu \mathrm{molm}^{-2} \mathrm{~s}^{-1}\right)$. Cada ensayo se realizó por triplicado. Finalmente, se determinó en cada réplica el crecimiento algal por recuento celular (número celml-1) mediante un microscopio óptico, utilizando una cámara de Neubauer, y se informó el valor promedio.

\section{Lactuca sativa}

El bioensayo con L. sativa var. Gallega se considera una prueba estática de toxicidad aguda y en este estudio se realizó con base en el protocolo propuesto por Sobrero y Ronco (2004), y la OECD (Test No 208; OECD, 2006) con modificaciones. Se colocaron 17 semillas en cada caja de Petri de $100 \mathrm{~mm}$ de diámetro, conteniendo un papel de filtro humedecido con $4 \mathrm{ml}$ de muestra. Como control negativo se utilizó agua dura reconstituida $\left(\mathrm{NaHCO}_{3} 192 \mathrm{mgl}^{-1}, \mathrm{CaSO}_{4} 120 \mathrm{mgl}^{-1}, \mathrm{MgSO}_{4} 120 \mathrm{mgl}^{-1}, \mathrm{KCl} 8 \mathrm{mgl}^{-1}\right)$. Cada 
ensayo se hizo por cuadruplicado. Una vez sembradas las semillas, las placas de Petri se incubaron por 24 h bajo luz blanca, a fin de estimular la germinación, según lo propuesto por Hunter y Burritt (2002), y luego en oscuridad por 120 h más. Durante la incubación, la temperatura se mantuvo a $22 \pm 2{ }^{\circ} \mathrm{C}$. Una vez finalizado el tiempo de incubación, se midió la longitud de la raíz y del tallo.

\section{Caenorhabditis elegans}

Para el ensayo con C. elegans se utilizóla cepa N2 de var. Bristol obtenida del Caenorhabditis Genetic Center (University of Minnesota, MN, USA) y mantenida en stock $\mathrm{a}-70^{\circ} \mathrm{C}$. Para el ensayo se utilizaron larvas en estadio de desarrollo sincronizado L1 (Lewis \& Fleming, 1995) de acuerdo con métodos estándar (ISO, 2010). Como respuesta toxicológica, se evaluó la longitud corporal (Höss et al., 2013). La exposición se llevó a cabo en placas de cultivo estériles de 24 pocillos. En cada uno de los pocillos se colocaron 10 nematodos en estadio L1, más $0.5 \mathrm{ml}$ de la muestra de agua, $15 \mu \mathrm{l}$ de medio Buffer M9 $\left(\mathrm{Na}_{2} \mathrm{HPO}_{4} 6 \mathrm{gl}^{-1}, \mathrm{KH}_{2} \mathrm{PO}_{4} 3 \mathrm{gl}^{-1}, \mathrm{NaCl} 5 \mathrm{gl}^{-1}\right.$, $\mathrm{MgSO}_{4} 0.12 \mathrm{gl}^{-1}$ ) y una concentración de biomasa de $E$. coli equivalente a $\mathrm{DO}_{600 \mathrm{~nm}}=1$, destinada a suplementar alimento ad libitum a las larvas de C. elegans. Los ensayos se hicieron por cuadruplicado. Las placas se 
incubaron por $96 \mathrm{~h}$ a $20{ }^{\circ} \mathrm{C}$. Transcurrido ese tiempo, se detuvo el crecimiento de los nematodos por calor ( $20 \mathrm{~min}$ a $50^{\circ} \mathrm{C}$ ) y se tiñeron con $0.25 \mathrm{ml}$ de solución de Rosa Bengala $\left(0.5 \mathrm{gl}^{-1}\right)$. Las muestras se fotografiaron utilizando un microscopio óptico Nikon Eclipse 50i a 40X de aumento (o 100X para gusanos en estadio L1), con una cámara digital acoplada Nikon CoolPix S10. A continuación, se midió la longitud del cuerpo a lo largo de su eje utilizando el software Image J (Schneider, Rasband, \& Eliceiri, 2012). Se estimó el crecimiento como la diferencia entre la longitud medida tras el ensayo (en $\mu \mathrm{m}$ ) y la longitud promedio al inicio (media de L1).

\section{Análisis de datos}

Los resultados de $P$. subcapitata, L. sativa y $C$. elegans se presentan como la elongación o el crecimiento relativo al control para comparar entre puntos y meses de muestreo de acuerdo con la siguiente ecuación:

CXrelativo $=1+\left[\frac{(\text { CPmuestra }- \text { CPcontrol })}{\text { CPcontrol }}\right]$ 
Siendo $C X_{\text {relativo }}$ el valor del crecimiento o elongación relativizado al control; $C P_{\text {muestra, el }}$ promedio del crecimiento obtenido para cada muestra, y $C P_{\text {control }}$ el crecimiento promedio del control. Se suma 1 para llevar el valor del control a la unidad y tener valores de crecimiento relativo positivos.

De esta manera, un $C X_{\text {relativo }}$ de 1 corresponde a un crecimiento de la muestra igual al control. Los valores mayores a 1 reflejan efectos de estimulación del crecimiento o de la elongación mientras que los valores menores a 1 corresponden a efectos de inhibición (Bagur-González, Estepa-Molina, Martín-Peinado, \& Morales-Ruano, 2011).

Con objeto de facilitar la comparación de los resultados de los tres bioensayos se realizó una categorización toxicológica con base en los valores del crecimiento relativo ( $C X_{\text {relativo }}$, según los siguientes criterios: no tóxico/sin efecto (1.3-0.91); levemente tóxico (0.90-0.75); moderadamente tóxico (0.74-0.51), y altamente tóxico (0.50-0). Los límites superior e inferior del rango no tóxico/sin efecto se establecieron a partir de los valores de crecimiento que no presentaron diferencias significativas respecto al control. La subdivisión del rango tóxico se estableció con base en el criterio para $C$. elegans utilizado por Clavijo et al. (2017). Se aplicó el mismo criterio para P. subcapitata y L. sativa, con la diferencia de que se incluyó la categoría de sobreestimulación (> 1.3).

Los resultados de los ensayos ecotoxicológicos se analizaron mediante un ANOVA de un factor, con un análisis a posteriori de comparaciones múltiples de Tukey para determinar diferencias 
significativas $(p<0.05)$. La variable respuesta que se consideró fue el crecimiento/elongación absolutos de los organismos utilizados en los bioensayos y la variable de agrupamiento fue el punto de muestreo. Las muestras se consideraron tóxicas en caso de encontrarse diferencias significativas con respecto al control. Este análisis se realizó utilizando el programa estadístico Infostat.

Para ver la relación entre los datos toxicológicos y los fisi coquímicos, se hizo un análisis de correlación de Spearman; el coeficiente de correlación fue testeado con nivel de significación del $5 \%$. Se optó por el coeficiente de Spearman porque no todos los parámetros fisicoquímicos cumplieron con los criterios de normalidad. Para el análisis de correlación se consideraron todos los valores obtenidos de los parámetros fisicoquímicos y los valores promedio de cada muestra analizada de los ensayos ecotoxicológicos. Además, se realizó un análisis de componentes principales (ACP) con la finalidad de detectar agrupamientos de observaciones multivariadas (parámetros fisicoquímicos) similares dentro del conjunto muestral (puntos de muestreo). Dichos análisis estadísticos se realizaron utilizando el programa $R$ (R Core Team, 2016).

\section{Resultados}




\section{Análisis de parámetros fisicoquímicos}

En la Tabla 2 se presentan los resultados del análisis fisicoquímico de las muestras de agua. En los diferentes puntos de muestreo, el $\mathrm{pH}$ se mantuvo en los tres monitoreos dentro del intervalo alcalino (7.97-8.66), cumpliendo con los niveles guía de ACUMAR para la protección de la biota. Considerando todo el periodo de análisis, el $72 \%$ de las muestras superaron la concentración máxima de $5 \mathrm{mgl}^{-1}$ para $\mathrm{DBO}_{5}$ establecida como nivel guía; de igual manera que para PT todas las muestras superaron la concentración máxima de $0.01 \mathrm{mgl}^{-1}$, variando en un intervalo de concentración entre 0.2 y $1.2 \mathrm{mgl}^{-1}$.

Tabla 2. Parámetros fisicoquímicos de las muestras de agua de los ríos Cañuelas y Navarrete.

\section{Parámetros fisicoquímicos}

\begin{tabular}{|c|c|c|c|c|c|c|c|c|c|c|c|}
\hline \multirow{2}{*}{ Mes } & \multirow{2}{*}{ Sitio } & CE & $\mathrm{pH}$ & \multicolumn{2}{|c|}{ OD } & \multirow{2}{*}{$\begin{array}{l}\mathrm{DBO}_{5} \\
\mathrm{mgl}^{-1}\end{array}$} & \multirow{2}{*}{$\begin{array}{l}\text { DQO } \\
\mathrm{mgl}^{-1}\end{array}$} & \multirow{2}{*}{$\begin{array}{c}\mathrm{DBO}_{5} / \\
\mathrm{DQO}\end{array}$} & \multirow{2}{*}{$\begin{array}{l}\text { NTK } \\
\text { mgl }^{-1}\end{array}$} & \multirow{2}{*}{$\begin{array}{c}\mathrm{N}-\mathrm{NO}_{3} \\
\mathrm{mgl}^{-1}\end{array}$} & \multirow{2}{*}{$\begin{array}{c}\text { PT } \\
\text { mgl-1 }^{-1}\end{array}$} \\
\hline & & $\mu \mathrm{Scm}^{-1}$ & & $\mathbf{m g l}^{-1}$ & $\%$ & & & & & & \\
\hline \multirow{2}{*}{ Noviembre } & $\mathrm{AC1}$ & 1469 & 8.22 & 5.47 & 67.8 & 14.0 & 60.7 & 0.23 & 9.80 & 0.21 & 0.6 \\
\hline & AC3 & 1223 & 8.14 & 4.29 & 50.4 & 8.0 & 28.8 & 0.27 & 5.12 & 0.70 & 1.0 \\
\hline
\end{tabular}


Tecnología y

Ciencias $\stackrel{\unlhd}{\unlhd}$ gua
2021, Instituto Mexicano de Tecnología del Agua

Open Access bajo la licencia CC BY-NC-SA 4.0

(https://creativecommons.org/licenses/by-nc-sa/4.0/)

\begin{tabular}{|c|c|c|c|c|c|c|c|c|c|c|c|}
\hline & $\overline{A N}$ & 848 & 8.44 & 8.48 & 102.0 & 7.0 & 20.9 & 0.33 & 2.32 & 0.65 & 1.1 \\
\hline \multirow{4}{*}{ Diciembre } & $\mathrm{AC1}$ & 2227 & 8.28 & 7.22 & 92.8 & 16.8 & 47.9 & 0.35 & 9.36 & 1.10 & 0.7 \\
\hline & AC2 & 1363 & 8.11 & 6.15 & 80.7 & 5.7 & 29.7 & 0.19 & 2.99 & 0.09 & 0.2 \\
\hline & AC3 & 2155 & 7.97 & 3.90 & 52.0 & 4.7 & 77.8 & 0.06 & 2.96 & 1.40 & 0.5 \\
\hline & AN & 1280 & 8.24 & 10.20 & 137.0 & 3.6 & 14.3 & 0.25 & 1.91 & 2.70 & 0.6 \\
\hline \multirow{4}{*}{ Febrero } & $\mathrm{AC1}$ & 3547 & 8.62 & 0.25 & 3.2 & 240.0 & 550.0 & 0.43 & 21.44 & 0.09 & 1.2 \\
\hline & AC2 & 2702 & 8.66 & 4.85 & 62.9 & 25.7 & 84.0 & 0.30 & 9.75 & 0.09 & 0.6 \\
\hline & AC3 & 2305 & 8.55 & 9.98 & 129.0 & 7.8 & 43.0 & 0.18 & 4.16 & 0.29 & 0.5 \\
\hline & AN & 1357 & 8.14 & 8.66 & 113.0 & 4.1 & 19.0 & 0.21 & 2.34 & 0.54 & 1.0 \\
\hline
\end{tabular}

En el muestreo realizado en el mes de noviembre se registraron los valores más bajos de CE (848-1 $\left.469 \mu \mathrm{Scm}^{-1}\right)$ respecto a los otros meses. En este muestreo, el punto $\mathrm{AC} 1$ presentó los valores mayores de $\mathrm{DBO}_{5}$ (14.0 mgl-1), DQO $\left(60.7 \mathrm{mgl}^{-1}\right)$ y NTK $\left(9.80 \mathrm{mgl}^{-1}\right)$, así como los valores menores de $\mathrm{N}-\mathrm{NO}_{3}-\left(0.21 \mathrm{mgl}^{-1}\right)$ y $\mathrm{PT}\left(0.6 \mathrm{mgl}^{-1}\right)$ en relación con los otros dos puntos de muestreo.

En diciembre tanto la $\mathrm{CE}$ como la concentración de $\mathrm{N}-\mathrm{NO}_{3}{ }^{-}$ registraron un notable aumento con respecto al mes anterior: 2227 $\mu \mathrm{Scm}^{-1}$ y $1.10 \mathrm{mgl}^{-1}$ en $\mathrm{AC} 1 ; 2155 \mu \mathrm{Scm}^{-1}$ y $1.40 \mathrm{mgl}^{-1}$ en AC3, y 1280 $\mu \mathrm{Scm}^{-1}$ y $2.70 \mathrm{mgl}^{-1}$ en AN. Además, se observó un aumento de la DQO (77.8 $\mathrm{mgl}^{-1}$ ) en AC3 con respecto al mes de noviembre. En la muestra del punto $A C 3$, se midió una concentración de OD de $3.90 \mathrm{mgl}^{-1}$, que estuvo por debajo del valor mínimo de $5 \mathrm{mgl}^{-1}$ establecido según la normativa. Dicho valor fue notablemente menor con relación al resto de los puntos 
de muestreo, cuyos valores fueron más cercanos a la saturación: 7.22 $\mathrm{mgl}^{-1}$ en $\mathrm{AC} 1 ; 6.15 \mathrm{mgl}^{-1}$ en $\mathrm{AC} 2$, y $10.20 \mathrm{mgl}^{-1}$ en AN.

En el mes de febrero, en la muestra del punto AC1 se registró una marcada disminución en la concentración de OD $\left(0.25 \mathrm{mgl}^{-1}\right)$, cuyo valor fue muy inferior al nivel guía $\left(5 \mathrm{mgl}^{-1}\right)$; mientras que se obtuvo un aumento tanto en los valores de CE (3 $547 \mathrm{mgl}^{-1}$ ) como en la concentración de $\mathrm{DBO}_{5}$ (240 $\left.\mathrm{mgl}^{-1}\right)$, de DQO (550 $\mathrm{mgl}^{-1}$ ) y de NTK (21.44 $\mathrm{mgl}^{-1}$ ). Estos cambios, aunque atenuados, también se observaron en el punto AC2 localizado aguas abajo de AC1. Cabe señalar que para todos los puntos de muestreo, los valores de CE fueron los más altos en este mes, en comparación con los otros meses analizados.

Considerando todo el periodo de estudio, las muestras de agua del punto AN presentaron los valores más altos de $O D$, mientras que los valores de $\mathrm{CE}_{2} \mathrm{DBO}_{5}, \mathrm{DQO}$ y NTK fueron los más bajos que se registraron.

Según el índice de biodegradabilidad, en el $54 \%$ de las muestras analizadas la materia orgánica se clasificó como moderadamente biodegradable (de 0.50 a 0.25 ). El valor más alto fue calculado en el punto AC1 (0.43) en el mes de febrero, indicando una mayor proporción de materia moderadamente biodegradable. El $36 \%$ de las muestras se clasificó como poco biodegradables, y sólo en la muestra del punto AC3 de diciembre se obtuvo un valor bajo (0.06), indicando la presencia de compuestos recalcitrantes, no biodegradables. 


\section{Bioensayos ecotoxicológicos}

En la Figura 2 se presentan los resultados del bioensayo realizado con $P$. subcapitata. En el $63 \%$ de las muestras analizadas se obtuvo una sobreestimulación significativa (ANOVA, $p<0.05$ ) del crecimiento relativo: 2.48 (AC2), 2.91 (AC3) y 2.55 (AN) para el mes de diciembre, y 2.34 (AC3) y 2.61 (AN) en febrero. Sin embargo, se observó una inhibición significativa $(p<0.05)$ del crecimiento en el punto AC1 (0.65) en el mes de diciembre, y en los puntos AC1 (0.18) y AC2 (0.59) en febrero.

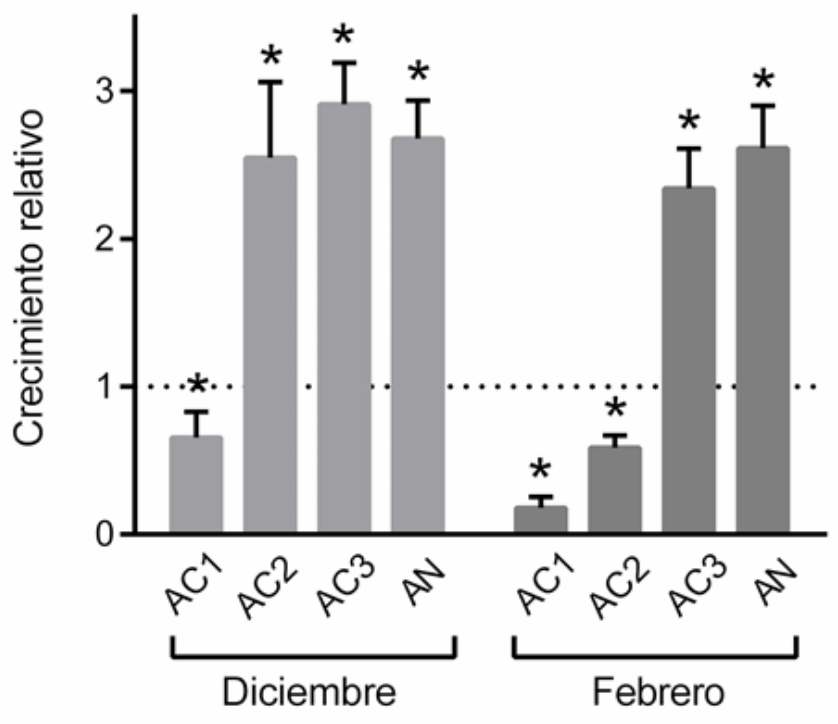


Figura 2. Crecimiento relativo de $P$. subcapitata. Las muestras con * presentaron un crecimiento relativo significativamente diferente respecto al control ( $p<0.05)$; la línea punteada indica el valor del control.

Los resultados de los bioensayos realizados de $L$. sativa se presentan en la Figura 3. Todas las muestras analizadas mostraron una sobreestimulación significativa $(p<0.05)$ de la elongación relativa del tallo (Figura 3b). El crecimiento relativo más alto se obtuvo en la muestra de agua del punto AC1 durante el mes de noviembre (1.68) y el valor más bajo en AC1 (1.33) en el mes de febrero. También en este último mes se observó que los valores obtenidos del crecimiento del tallo aumentaron entre las muestras de agua de los puntos de muestreo, coincidiendo con el sentido del cauce del arroyo A. Cañuelas (AC2 1.40 y AC3 1.48), siendo el valor hallado del agua recolectada del río A. Navarrete similar a la muestra del punto AC3 (AN 1.49). 
Tecnología y

\section{Ciencias $₫$ Agua}

2021, Instituto Mexicano de Tecnología del Agua

Open Access bajo la licencia CC BY-NC-SA 4.0

(https://creativecommons.org/licenses/by-nc-sa/4.0/)
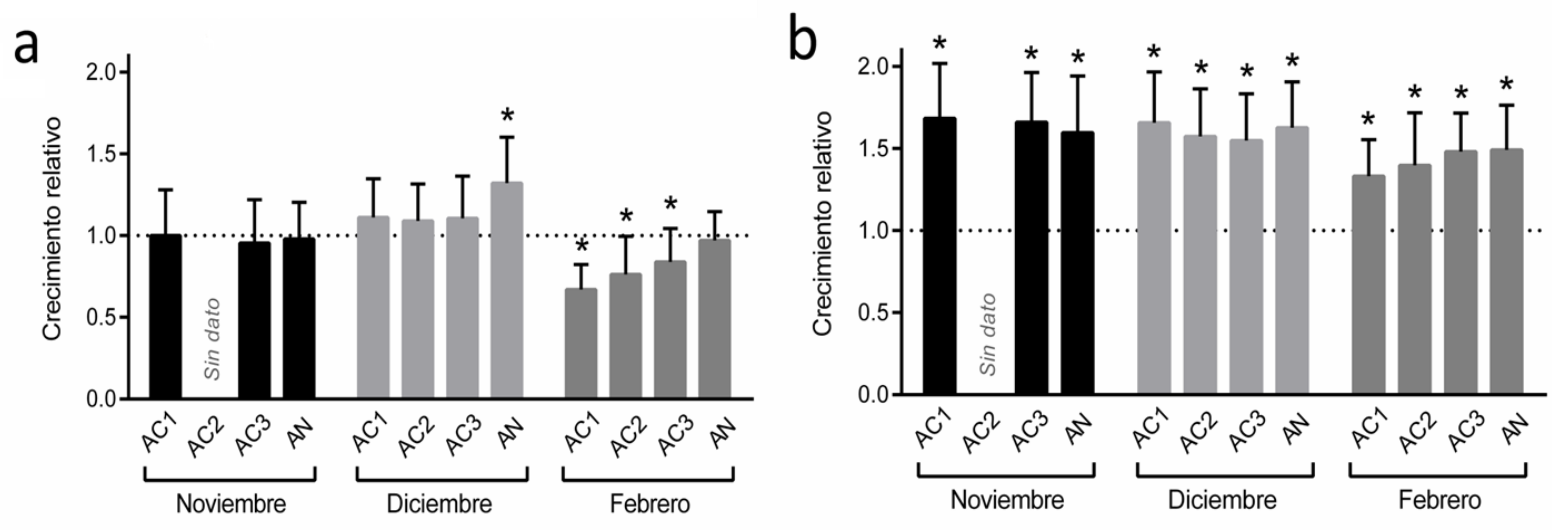

Figura 3. a) Crecimiento relativo de la raíz y b) el tallo de L. sativa. Las muestras con * presentaron un crecimiento relativo significativamente diferente respecto al control ( $p<0.05)$; la línea punteada indica el valor del control.

Respecto a la elongación de la raíz (Figura 3a), en el mes de noviembre se determinaron valores de crecimiento relativos cercanos al control en las muestras de agua recolectadas en los sitios AC1 (1.00), AC3 (0.95) y AN (0.98). Contrariamente, los valores de crecimiento relativo de la elongación obtenidos en el mes de diciembre mostraron una sobreestimulación de la raíz en todas las muestras de agua de todos los puntos analizados (1.11 en AC1; 1.09 en AC2; 1.11 en AC3), siendo el punto AN (1.32) donde el crecimiento fue significativamente $(p<0.05)$ mayor al control. En el mes de febrero, las muestras de agua de tres de los puntos presentaron una inhibición significativa en la elongación de la raíz ( 0.67 en $A C 1 ; 0.76$ en $A C 2$, y 0.84 en $A C 3$ ). Cabe destacar que en este mes tanto la elongación del tallo como la de la raíz registraron los 
valores más bajos, presentando un aumento gradual del crecimiento en el siguiente orden: AC1 < AC2 < AC3 < AN.

Los crecimientos relativos de $C$. elegans se muestran en la Figura 4. Los bioensayos con $C$. elegans revelaron inhibiciones significativas ( $p$ $<0.05)$ respecto al control tanto en las muestras de agua de los sitios AC1 (0.91) y AN (0.86) del mes de noviembre, como en AC2 (0.91) y AN (0.88) del mes de diciembre. Es preciso señalar que en el mes de febrero no se detectaron diferencias en las muestras de agua recolectadas con respecto al control.

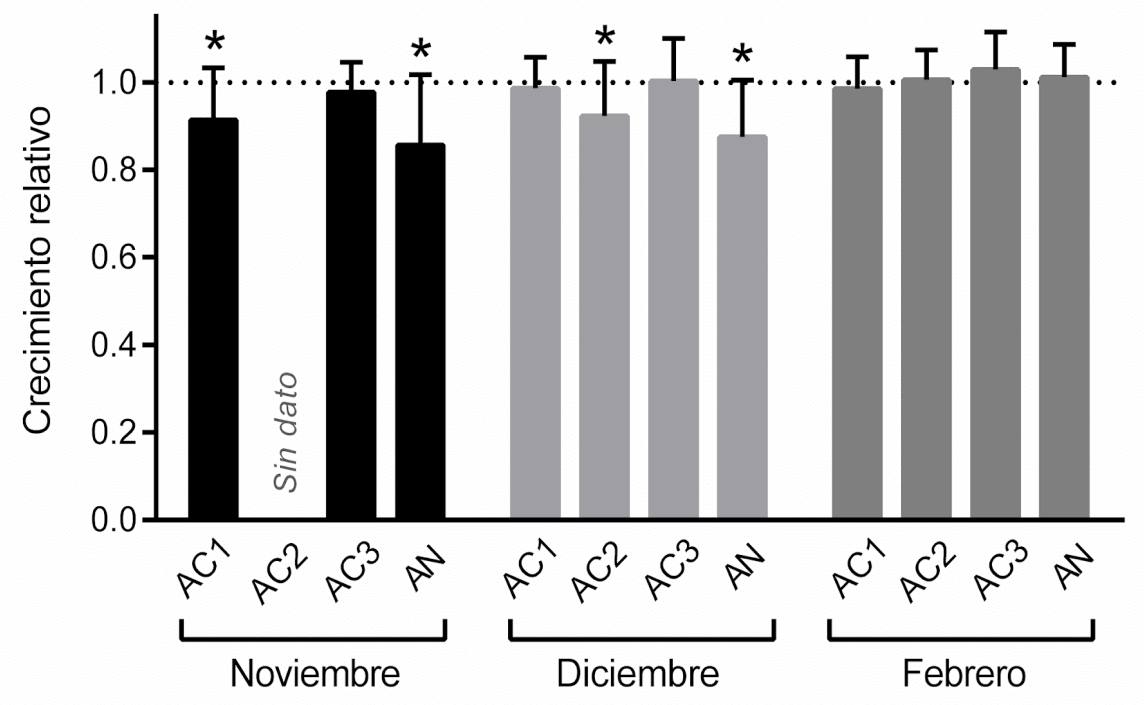

Figura 4. Crecimiento relativo de C. elegans. Las muestras con* presentaron un crecimiento relativo significativamente diferente respecto al control ( $p<0.05$ ); la línea punteada indica el valor del control. 
En la Tabla 3 se presentan los valores de crecimiento relativo. Se asignan diferentes colores por categoría toxicológica, con el fin de poder comparar de manera visual los resultados de los tres bioensayos, y se señalan aquellos casos en los que se observaron efectos tóxicos.

Tabla 3. Categorías toxicológicas basadas en el crecimiento relativo de los organismos de los bioensayos ecotoxicológicos. Los rangos de toxicidad son sobreestimulación (> 1.30) en azul; no tóxico/sin efecto (1.30-0.91) en verde; levemente tóxico (0.90-0.75) en amarillo; moderadamente tóxico (0.74-0.51) en naranja, y altamente tóxico (0.50-0) en rojo. En gris se indica la ausencia de datos.

\begin{tabular}{|c|c|c|c|c|c|c|c|c|c|c|c|c|}
\hline \multirow{3}{*}{ Bioensayo } & \multicolumn{12}{|c|}{ Muestra } \\
\hline & \multicolumn{4}{|c|}{ Noviembre } & \multicolumn{4}{|c|}{ Diciembre } & \multicolumn{4}{|c|}{ Febrero } \\
\hline & AC1 & AC2 & AC3 & AN & AC1 & AC2 & AC3 & AN & AC1 & AC2 & AC3 & AN \\
\hline \multirow{2}{*}{ L. sativa } & 1.00 & & 0.95 & 0.98 & 1.11 & 1.09 & 1.11 & 1.32 & 0.67 & 0.76 & 0.84 & 0.97 \\
\hline & 1.68 & & 1.66 & 1.60 & 1.66 & 1.57 & 1.55 & 1.63 & 1.33 & 1.40 & 1.48 & 1.49 \\
\hline P. subcapitata & & & & & 0.65 & 2.55 & 2.91 & 2.68 & 0.18 & 0.59 & 2.34 & 2.61 \\
\hline C. elegans & 0.91 & & 0.98 & 0.86 & 0.99 & 0.91 & 1.00 & 0.88 & 0.98 & 1.00 & 1.03 & 1.01 \\
\hline
\end{tabular}

En el mes de noviembre se pudo observar un leve efecto tóxico en C. elegans en las muestras de agua recolectadas de los sitios AC1 y AN. En el mes de diciembre, $P$. subcapitata mostró un efecto moderadamente 
tóxico con el agua del punto $\mathrm{AC} 1$; mientras que $C$. elegans presentó un efecto levemente tóxico con las muestras de agua tanto del sitio AC2 como del sitio AN. Por otro lado, en el mes de febrero, P. subcapitata presentó un efecto altamente tóxico con las muestras de agua del punto AC1 y levemente tóxico en el punto AC2; mientras que para la raíz de $L$. sativa, en todas las muestras de agua recolectadas de los sitios del arroyo Cañuelas (AC1, AC2 y AC3), se detectaron niveles bajos y leves de toxicidad. Estos niveles de toxicidad disminuyeron conforme avanza el curso de agua. Se destaca que en todas las muestras analizadas se obtuvieron efectos de sobreestimulación significativos respecto del control en el tallo de L. sativa.

\section{Análisis estadístico}

En la Tabla 4 se presenta el análisis de correlación de "a pares" de Spearman realizado con base en los datos fisicoquímicos y el promedio de las réplicas de los correspondientes bioensayos ecotoxicológicos.

Tabla 4. Coeficientes de correlación de Spearman. Los valores de correlación significativos $(p<0.05)$ se indican con negrita. 
Tecnología y

Ciencias $₫$ Agua
2021, Instituto Mexicano de Tecnología del Agua

Open Access bajo la licencia CC BY-NC-SA 4.0

(https://creativecommons.org/licenses/by-nc-sa/4.0/)

\begin{tabular}{|c|c|c|c|c|c|c|c|c|c|c|c|}
\hline & \multicolumn{7}{|c|}{ Parámetros fisicoquímicos } & \multicolumn{4}{|c|}{ Ensayos ecotoxicológicos } \\
\hline & $E \quad P H$ & OD & $\mathrm{DBO}_{5}$ & DQO & NTK & $\mathrm{N}-\mathrm{NO}_{3}^{-}$ & PT & $\begin{array}{c}\text { L. } \\
\text { sativa } \\
\text { (Raíz) }\end{array}$ & $\begin{array}{c}L . \\
\text { sativa } \\
\text { (Tallo) }\end{array}$ & $\begin{array}{c}P . \\
\text { subcapi- } \\
\text { tata }\end{array}$ & C. ele-gans \\
\hline$\overline{C E}$ & 0.576 & -0.382 & 0.636 & 0.845 & 0.700 & -0.303 & 0.088 & -0.418 & -0.636 & -0.762 & 0.600 \\
\hline $\mathrm{PH}$ & & -0.095 & 0.507 & 0.476 & 0.559 & -0.392 & 0.301 & -0.714 & -0.648 & -0.929 & 0.132 \\
\hline OD & & & -0.564 & -0.755 & -0.636 & 0.408 & -0.258 & 0.364 & 0.155 & 0.238 & -0.045 \\
\hline $\mathrm{DBO}_{5}$ & & & & 0.755 & 0.918 & -0.299 & 0.507 & -0.573 & -0.164 & -0.833 & 0.136 \\
\hline DQO & & & & & 0.809 & -0.302 & 0.460 & 0.460 & -0.445 & 0.571 & 0.327 \\
\hline NTK & & & & & & -0.419 & 0.390 & -0.518 & -0.164 & -0.833 & 0.218 \\
\hline $\mathrm{N}-\mathrm{NO}_{3}{ }^{-}$ & & & & & & & -0.096 & 0.793 & 0.462 & 0.367 & -0.359 \\
\hline PT & & & & & & & & -0.422 & -0.222 & -0.504 & -0.025 \\
\hline L. sativa & a (Raíz) & & & & & & & & 0.618 & 0.524 & -0.418 \\
\hline L. sativa & $a$ (Tallo) & & & & & & & & & 0.429 & -0.545 \\
\hline P. subcap & apitata & & & & & & & & & & 0.071 \\
\hline C. elegan & ans & & & & & & & & & & \\
\hline
\end{tabular}

Los parámetros que presentaron una correlación significativa al 5 \% se describen a continuación. Dentro de los fisicoquímicos, DBO 5, DQO y NTK presentaron una buena correlación entre ellos ( $r \geq 0.755)$. A su vez, este grupo de tres parámetros tuvo una correlación positiva con la CE ( $r$ $\geq$ 0.636). De ese grupo, DQO y NTK mostraron una correlación significativa de signo negativo con el OD $(r<-0.755$ y -0636 , respectivamente).

De las determinaciones ecotoxicológicas, la longitud de la raíz de $L$. sativa presentó una correlación positiva con $\mathrm{N}-\mathrm{NO}_{3}^{-}(r=0.793)$ y negativa con $\mathrm{pH}(r=-0.715)$, mientras que la longitud del tallo presentó una 
correlación negativa tanto con la CE como con el pH ( $r=-0.636$ y -0.648 respectivamente). Por otro lado, el recuento celular de $P$. subcapitata mostró una correlación negativa con CE $(r=-0.762)$, pH $(r=-0.929)$, $\mathrm{DBO}_{5}(r=-0.833)$ y NTK $(r=-0.833)$. Por último, se destaca que los valores de crecimiento de C. elegans no correlacionaron de manera significativa con ninguno de los parámetros fisicoquímicos analizados.

Con base en las observaciones multivariadas, se obtuvo la expresión matemática que describe la CP1 y la CP2 mediante las siguientes ecuaciones:

$$
\begin{aligned}
& C P 1=0.35 . Z_{O D}+0.22 . Z_{N N O 3}-\left[0.43\left(Z_{D B O 5}+Z_{D Q O}+Z_{N T K}\right)+0.38 . Z_{C E}+0.28 . Z_{p H}+0.22 . Z_{P T}\right] \\
& C P 2=0.67 . Z_{P T}+0.57 . Z_{N N O 3}+0.19 . Z_{D B O 5}+0.16 . Z_{D Q O}-\left[0.30 . Z_{p H}+0.26 . Z_{C E}\right]
\end{aligned}
$$

Los parámetros que contribuyen con el mayor peso en la CP1 son

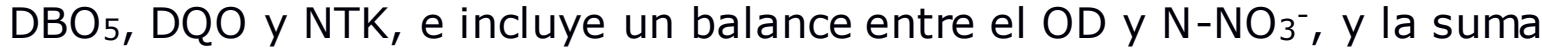
de $\mathrm{DBO}_{5}, \mathrm{DQO}$ y NTK más $\mathrm{CE}$, y en menor medida pH y PT. En la CP2 se obtuvo un balance entre la sumatoria del $\mathrm{PT}$, el $\mathrm{N}^{-\mathrm{NO}_{3}}{ }^{-}$y la $\mathrm{DBO}_{5}$ y DQO, en contraposición con $\mathrm{pH}$ y CE. Los valores de las $Z$ son los datos normalizados por la media y el desvío estándar de cada variable estadística.

En la Figura 5 se presenta el ACP donde el primer componente (CP1) se lleva el $60 \%$ de la variabilidad de los datos, mientras que CP1 y CP2 conjuntamente reúnen el $73 \%$ de la variabilidad total. En el cuadrante positivo tanto de la CP1 como de la CP2 se puede observar que los puntos 
de muestreo de AN se encuentran agrupados, lo cual indica una alta homogeneidad entre los valores de los parámetros fisicoquímicos de esas muestras. Es así como en estas muestras extraídas en AN, en comparación con las demás, predominan las concentraciones más altas de OD, PT y $\mathrm{N}^{-\mathrm{NO}_{3}}{ }^{-}$y los menores valores de CE. Por otra parte, las muestras de los puntos AC1 y AC2 presentan una mayor dispersión en el eje de la CP1; mientras que en las muestras de AC3, su dispersión se manifiesta a lo largo de la CP2. Puntualmente, las muestras de AC1 y de AC2 (muestreo de febrero) se hallaron en el eje negativo de la CP1, descritas por un valor muy bajo de OD, y valores altos de DQO y DBO. Respecto de la CP2, el parámetro que permitió diferenciar las muestras fue el NTK, hallándose en el eje negativo aquellas muestras que presentaron un mayor valor de este parámetro.

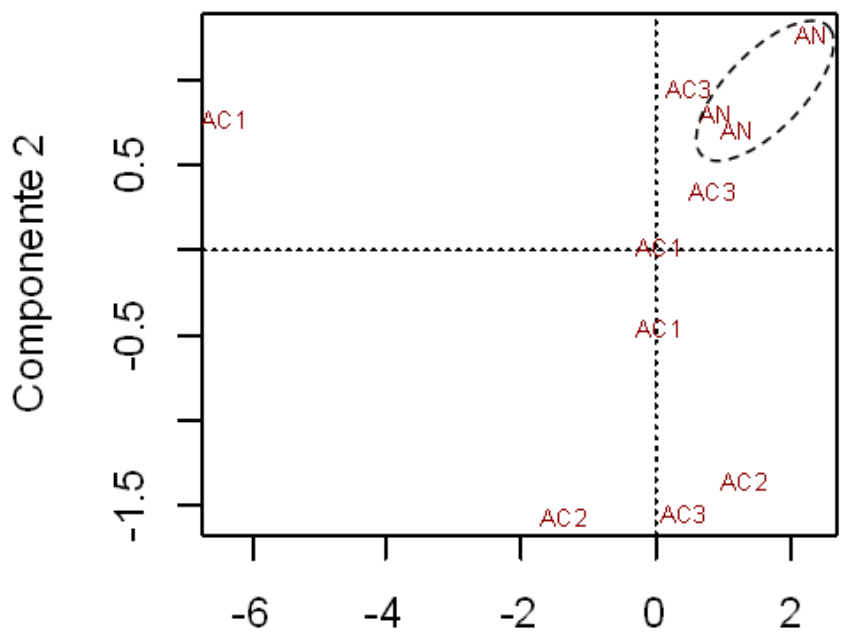

Componente 1 
Figura 5. Análisis de componentes principales de los parámetros fisicoquímicos.

\section{Discusión}

El arroyo Cañuelas es uno de los tributarios principales de la Cuenca Matanza Riachuelo, considerada una de las más contaminadas de Argentina. Si bien su cauce atraviesa algunos sectores donde aún se conservan ambientes naturales, presenta un moderado nivel de contaminación debido a descargas de efluentes industriales y domésticos. Para garantizar la conservación de estos ambientes y prevenir un mayor deterioro futuro de la cuenca, este trabajo destaca la importancia de realizar una evaluación integrada de la calidad del agua que contemple los aspectos tóxicos en conjunto con los estudios tradicionales basados en la determinación de parámetros fisicoquímicos y bacteriológicos.

Durante el periodo de estudio se observó un mayor deterioro de la calidad de agua en el punto de muestreo río arriba del A. Cañuelas (AC1), caracterizado por un aumento tanto de $\mathrm{DBO}_{5}, \mathrm{DQO}$, así como de NTK, en particular durante diciembre y febrero. El aumento de los valores de estos parámetros, junto con los altos valores de correlación hallados entre el los, 
da cuenta de una contaminación que se caracteriza por una alta concentración de materia orgánica nitrogenada y carbonada debido posiblemente a las descargas de efluentes de industrias lácteas y frigoríficos próximas al arroyo. Más aún, los valores de estos parámetros van disminuyendo a medida que discurre el arroyo, desde AC1 hasta el punto AC3, lo que indica un efecto de dilución.

Es importante subrayar que tanto la disminución de los valores absolutos de $\mathrm{DBO}_{5}$ y DQO, como el índice de biodegradabilidad y el NTK dan información sobre una mayor tasa de remoción de la materia orgánica biodegradable respecto de otros tipos de compuestos presentes, lo que da cuenta de la capacidad de autodepuración del río. En esta transformación intervienen diferentes procesos fisicoquímicos, pero principalmente biológicos, tales como la actividad bacteriana heterotrófica que utiliza la materia orgánica como alimento y fuente de energía para su metabolismo y reproducción (Berman \& Bronk, 2003). Así también, las plantas macrófitas contribuyen con la eliminación de nutrientes de la columna de agua, especialmente nitrógeno y fósforo (Dodkins et al., 2012); la oxigenación del agua (Albertoni, Palma-Silva, Trindade, \& Furlanetto, 2014), y la sedimentación (Cronin, Lewis Jr., \& Schiehser, 2006).

Por otra parte, durante el periodo de muestreo localizado en el A. Navarrete (punto AN) se obtuvieron altas concentraciones de oxígeno y bajos niveles de $\mathrm{DBO}_{5}$, DQO y NTK, cumpliendo con los niveles guía de la ACUMAR para Protección de biota, lo que indica una aparente mejor calidad del agua en comparación con el A. Cañuelas. Estas diferencias en 
cuanto a la composición fisicoquímica de las aguas del A. Cañuelas y del A. Navarrete se han confirmado mediante el análisis de componentes principales, donde las muestras del sitio AN presentaron un comportamiento homogéneo, mientras que los puntos restantes obtuvieron valores muy dispersos entre las CP1 y CP2.

En este punto de muestreo se verifica un balance para el OD con valores que tienden a producir una CP1 positiva; y valores de PT y/o N$\mathrm{NO}_{3}$ - superiores a su respectiva media, lo que produce una CP2 positiva. Para los restantes puntos de muestreo se obtuvieron valores muy dispersos entre las CP1 y CP2.

Cabe señalar que si bien todas las muestras analizadas presentaron valores de PT por encima del nivel guía establecido por ACUMAR, estos ambientes acuáticos de la región pampeana presentan naturalmente altas concentraciones de nutrientes, tal como lo describe el trabajo de Messetta, Hegoburu, Casas-Ruiz, Butturini y Feijoó (2017). Considerando los datos históricos de muestreos realizados por la ACUMAR, que incluyen determinaciones desde 2008, se observó que los valores obtenidos para todos los parámetros analizados se encuentran dentro del intervalo de variación, que además reflejaría las descargas periódicas de efluentes de las industrias locales que dan cuenta de episodios de contaminación recurrentes.

Respecto a los bioensayos con el alga $P$. subcapitata, se observó un marcado efecto de inhibición de su crecimiento en el punto AC1 durante diciembre y febrero. Dicha respuesta fitotóxica se atenuó 
siguiendo el cauce del río simultáneamente con la modificación en los parámetros fisicoquímicos, lo cual sugiere un efecto de dilución de los agentes causantes de la toxicidad. El efecto tóxico podría estar relacionado, en parte, con la presencia de compuestos nitrogenados o de otros compuestos asociados, dada la correlación negativa del crecimiento algal con NTK, parámetro que mide en forma conjunta tanto compuestos orgánicos nitrogenados como amoniacales. De la totalidad de compuestos amoniacales, el $\mathrm{NH}_{3}$ presenta niveles de toxicidad más altos para los organismos acuáticos que el $\mathrm{NH}_{4}{ }^{+}$. Las concentraciones relativas de $\mathrm{NH}_{4}{ }^{+}$ y de $\mathrm{NH}_{3}$ al ser dependientes del $\mathrm{pH}$ y de la temperatura del agua, y a valores mayores de ambos parámetros, la concentración de $\mathrm{NH}_{3}$ tiende a aumentar y la de $\mathrm{NH}_{4}{ }^{+}$a disminuir (Camargo \& Alonso, 2006; Collos \& Harrison, 2014). Considerando el pH alcalino de las muestras y la temperatura del agua, es posible que la toxicidad exhibida provenga de compuestos amoniacales.

Por otra parte, en el resto de las muestras analizadas se observó un efecto de sobreestimulación del crecimiento que podría deberse a altas concentraciones de nutrientes. El efecto de sobreestimulación también ha sido observado por otros autores como Olguín et al. (2004) y Salibián (2006) en algas expuestas a muestras de aguas del río Reconquista, el cual se encuentra en la misma región pampeana que el A. Cañuelas.

En el caso del bioensayo con L. sativa, las respuestas en la raíz y en el tallo mostraron resultados diferentes. En todas las muestras analizadas, la elongación del tallo presentó una sobreestimulación del crecimiento con respecto al control. Contrariamente, la raíz mostró 
respuestas tanto de sobreestimulación como de inhibición de la elongación dependiendo de las variaciones fisicoquímicas presentes en las muestras a las que fueron expuestas. Otros autores han descrito la sobreestimulación en la elongación de la raíz y del tallo de L. sativa como respuesta a altas concentraciones de nutrientes tanto de origen natural como antrópico, como los trabajos de Bohórquez-Echeverry y CamposPinilla (2007), y Solano-Padilla (2007) en muestras de agua extraídas del río Bogotá y en aguas residuales utilizadas para de la producción de cultivos en la sabana de Bogotá, Colombia. En efecto, la correlación significativa de la elongación de la raíz con la concentración de $\mathrm{N}^{-\mathrm{NO}_{3}}$ confirma que este elemento es uno de los nutrientes limitantes del crecimiento de la planta $(r=0.793)$.

En el mes de febrero, en coincidencia con los resultados obtenidos para $P$. subcapitata, la raíz y el tallo de $L$. sativa presentaron los menores crecimientos en $\mathrm{AC1}$, los cuales fueron aumentando de modo paulatino conforme el avance del arroyo. La toxicidad observada en las raíces en estas muestras podría deberse a los altos niveles de salinidad, que producirían un cambio en la presión osmótica, tal como fue observado por diversos autores (Young et al., 2012; Aguiar, Andrade-Vieira, \& De Olivera-David, 2016), y eso puede sustentarse en la correlación negativa obtenida entre los parámetros biológicos y la CE. Así también, tal como se describió en algas, la presencia de compuestos amoniacales sugerido por los altos niveles de NTK, podría estar asociada con efectos fitotóxicos en estudios con L. sativa, tal como lo sugieren Rodríguez-Romero et al. 
(2014), al emplear este organismo para el análisis de aguas superficiales expuestas a vuelco de aguas residuales en el río Chalma en México.

En términos generales, los resultados obtenidos mostraron una mayor sensibilidad de la raíz como indicador de fitotoxicidad respecto a la elongación del tallo en concordancia con lo descrito por otras fuentes (Wang, 1991; Campagna-Fernandes, Marin, \& Penha, 2016; Priac et al., 2017). Esta mayor sensibilidad de la raíz se explica por su rol principal en los procesos de absorción y, por ende, su estrecho contacto con los contaminantes del medio (González Pérez et al., 2012). Por otro lado, la sobreestimulación del tallo observada a lo largo de este trabajo, si bien podría no ser considerado tóxico per se, sí podría alertar sobre un aumento de la productividad (proceso de eutrofización) que conlleva un posible deterioro de la calidad del agua (Camargo \& Alonso, 2007; Rodríguez-Romero et al., 2014).

La respuesta de $C$. elegans mostró variaciones durante el periodo de estudio, observándose la mayor inhibición del crecimiento en los meses de noviembre y diciembre, en particular en el punto de muestreo AN, el cual presentó una aparente mejor calidad fisicoquímica con respecto a los niveles guía establecidos por la ACUMAR para protección de biota. Si bien sólo se halló una correlación débil con la $\mathrm{CE}$, la falta de correlación con los restantes parámetros fisicoquímicos analizados indicaría que el efecto levemente tóxico observado podría deberse a la presencia de compuestos no determinados en este trabajo. Como parte de los resultados de este trabajo, la falta de correlación del nematodo con la concentración de nutrientes permite proponer a este modelo como apto para cuantificar 
efectos tóxicos en aguas mesotróficas o eutróficas, ofreciendo una ventaja en comparación con los bioensayos que emplean organismos fotosintéticos donde el efecto de los nutrientes puede solapar los tóxicos. En virtud de sus múltiples ventajas, este modelo está ganando apoyo e interés internacional para su aplicación en estudios de ambientes acuáticos (Leung et al., 2008; Haegerbaeumer et al., 2016; Clavijo et al., 2016). No obstante, en este trabajo se refuerza la postura de emplear distintos bioensayos que presentan diversas sensibilidades a los compuestos en muestras ambientales, de manera que en conjunto permiten ponderar los efectos tóxicos (Ferrari, 2015).

Los resultados en este trabajo muestran que el agua recolectada de los sitios de los arroyos Cañuelas y Navarrete influyeron de manera disímil en las respuestas tóxicas de los organismos considerados como sensores, indicando composiciones químicas diferentes con altos niveles de contaminación orgánica en los puntos AC1 y AC2 en los meses de diciembre y febrero con efectos fitotóxicos tanto en $P$. subcapitata como en la raíz de $L$. sativa. Por otro parte, como ya se señaló, C. elegans mostró mayor sensibilidad a las muestras del punto AN, posiblemente debido a la presencia de compuestos no determinados en este trabajo. Las diferentes respuestas obtenidas mediante el uso de los tres bioensayos permitieron hacer una caracterización toxicológica que en conjunto con la información fisicoquímica generó una evaluación integral de la calidad del agua de los arroyos. Si bien el organismo de gestión de cuenca y otros organismos gubernamentales de Argentina aún no incorporan ensayos toxicológicos en sus normativas, este trabajo 
contribuye con la tendencia internacional de incorporarlos como herramienta útil en el análisis de calidad de agua.

\section{Conclusiones}

La aplicación de los bioensayos toxicológicos permitió ampliar la información sobre la calidad del agua de los arroyos estudiados. El A. Cañuelas presentó eventos de contaminación por materia orgánica biodegradable río arriba y altas concentraciones de nutrientes que podrían dar cuenta de la respuesta de sobreestimulación en $L$. sativa y $P$. subcapitata. Si bien este efecto no descarta la presencia de compuestos tóxicos, sí podría reflejar un aumento en la productividad biológica que conlleva a procesos de eutroficación, deteriorando la calidad del agua. Por otra parte, al analizar el arroyo Navarrete, C. elegans permitió observar un efecto inhibitorio en su crecimiento, lo cual indica la presencia de tóxicos en las muestras analizadas, a pesar de cumplir con los niveles guía propuestos por los entes de control. Los organismos utilizados para este estudio mostraron diferentes niveles de toxicidad y sensibilidad a las muestras ambientales, aportando información relevante respecto de la presencia de compuestos tóxicos. Dada la presente diversidad en las 
respuestas biológicas, es que se propone la complementariedad de los bioensayos como una herramienta útil para evaluar el impacto de la contaminación en los cuerpos de agua. Estos resultados constituyen un antecedente más para considerar la inclusión de los bioensayos en futuros planes de gestión de los recursos hídricos de la cuenca del arroyo Cañuelas y de otras cuencas nacionales e internacionales.

\section{Referencias}

ACUMAR, Autoridad de Cuenca Matanza Riachuelo. (2016). Establecimientos de seguimiento particular por su relevancia ambiental. Recuperado

de http://old.acumar.gob.ar/pagina/3475/seguimiento\%20particular. $11 / 10 / 2016$

ACUMAR, Autoridad de Cuenca Matanza Riachuelo. (2017). Resolución No 46/17. Límites Admisibles de Vertido de Efluentes Líquidos, Usos y Objetivos de Calidad de Agua y Declaración de Agente Contaminante. Recuperado de http://www.acumar.gob.ar

ACUMAR, Autoridad de Cuenca Matanza Riachuelo. (2018). Base de datos hidrográfica. Recuperado de http://www.bdh.acumar.gov.ar/bdh.

Abdalla, K. Z., \& Hammam, G. (2014). Correlation between biochemical oxygen demand and chemical oxygen demand for various wastewater treatment plants in Egypt to obtain the biodegradability indices. International Journal of Sciences: Basic and Applied Research, 13(1), 42-48. 
Aguiar, L. L., Andrade-Vieira, L. F., \& De Olivera-David, J. A. (2016). Evaluation of the toxic potential of coffee wastewater on seeds, roots and meristematic cells of Lactuca sativa L. Ecotoxicology and Environmental Safety, 133, 366-372.

Albertoni, E. F., Palma-Silva, C., Trindade, C. R. T., \& Furlanetto, L. M. (2014). Field evidence of the influence of aquatic macrophytes on water quality in a shallow eutrophic lake over a 13-year period. Acta Limnologica Brasiliensia, 26(2), 176-185.

APHA, American Public Health Association. (2012). Standard methods for the examination of water and wastewater (22st ed.). Washington, DC, USA: American Public Health Association.

Arias, T. L., Peralta, V. F., De Diana, D. M. F., Delgado, E. G., Márquez, F. S. A., Martínez, M. D. B., \& Bareiro, C. G. M. (2016). Índices de calidad ambiental de aguas del arroyo Caañabe mediante tests microbiológicos y ecotoxicológico. Revista Ambiente y Agua, 11(3), 548-565.

Bagur-González, M. G., Estepa-Molina, C., Martín-Peinado, F., \& MoralesRuano, S. (2011). Toxicity assessment using Lactuca sativa $L$. bioassay of the metal (loid) s As, Cu, Mn, Pb and $\mathrm{Zn}$ in soluble-inwater saturated soil extracts from an abandoned mining site. Journal of Soils and Sediments, 11(2), 281-289.

Bakker, K., \& Cook, C. (2011). Water governance in Canada: Innovation in the context of fragmentation. International Journal of Water Resources Development, 27(2), 275-289. 
Barceló, D., \& López, M. J. (2008). Contaminación y calidad química del agua: el problema de los contaminantes emergentes. Memorias. Jornadas de presentación de resultados: el estado ecológico de las masas de agua. Panel Científico-Técnico de Seguimiento de la Política de Aguas. Sevilla, España. Rcuperado de http://www.fnca.eu/phocadownload/P.CIENTIFICO/inf_contaminac ion.pdf.

Berman, T., \& Bronk, D. A. (2003). Dissolved organic nitrogen: A dynamic participant in aquatic ecosystems. Aquatic Microbial Ecology, 31(3), 279-305.

Berros, M. V. (2012). Relatos sobre el río, el derecho de la Cuenca Matanza Riachuelo. Revista de Derecho Ambiental, 1(1), 111-163.

Bohórquez-Echeverry, P., \& Campos-Pinilla, C. (2007). Evaluación de Lactuca sativa y Selenastrum capricornutum como indicadores de toxicidad en aguas. University Science, 12(2), 83-98.

Boudou, A., \& Ribeyre, F. (1997). Aquatic ecotoxicology: From the ecosystem to the cellular and molecular levels. Environmental Health Perspectives, 105(1), 21-35.

Camargo, J. A., \& Alonso, Á. (2006). Ecological and toxicological effects of inorganic nitrogen pollution in aquatic ecosystems: A global assessment. Environment International, 32(6), 831-849.

Camargo, J. A., \& Alonso, A. (2007). Contaminación por nitrógeno inorgánico en los ecosistemas acuáticos: problemas 
medioambientales, criterios de calidad del agua, e implicaciones del cambio climático. Ecosistemas, 16(2), 1-13.

Campagna-Fernandes, A. F., Marin, E. B., \& Penha, T. H. F. L. (2016). Application of root growth endpoint in toxicity tests with lettuce (Lactuca sativa). Ecotoxicology and Environmental Contamination, $11(1), 27-32$.

Casal, L. (2004). Turismo rural en Cañuelas: análisis del potencial de una nueva alternativa económica para la zona de abasto sur (tesis de Licenciatura en Economía Agraria). Facultad de Agronomía. Universidad de Buenos Aires, Buenos Aires, Argentina. Recuperado de http://www.agro.uba.ar

Castillo-Morales, G. (2004). Ensayos toxicológicos y métodos de evaluación de calidad de aguas: Estandarización, intercalibración, resultados y aplicaciones. Jiutepec, México: Instituto Mexicano de Tecnología del Agua.

Clavijo, A., Kronberg, M. F., Rossen, A., Moya, A., Calvo, D., Salatino, S. E., Pagano, E. A., Morábito, J. A., \& Munarriz, E. R. (2016). The nematode Caenorhabditis elegans as an integrated toxicological tool to assess water quality and pollution. Science of the Total Environment, 569-570, 252-261.

Clavijo, A., Rossen, A., Calvo, D., Kronberg, M. F., Moya, A., Pagano, E. A., \& Munarriz, E. R. (2017). Water quality and toxicological impact assessment using the nematode Caenorhabditis elegans bioassay in 
a long-term intensive agricultural area. Water, Air and Soil Pollution, 228(9), 333.

Collos, Y., \& Harrison, P. J. (2014). Acclimation and toxicity of high ammonium concentrations to unicellular algae. Marine Pollution Bulletin, 80(1-2), 8-23.

Connon, R. E., Geist, J., \& Werner, I. (2012). Effect-based tools for monitoring and predicting the ecotoxicological effects of chemicals in the aquatic environment. Sensors, 12(9), 12741-12771.

Cronin, G., Lewis Jr., W. M., \& Schiehser, M. A. (2006). Influence of freshwater macrophytes on the littoral ecosystem structure and function of a young Colorado reservoir. Aquatic Botany, 85(1), 3743.

Dodkins, I., Aguiar, F., Rivaes, R., Albuquerque, A., Rodríguez-González, P., \& Ferreira, M. T. (2012). Measuring ecological change of aquatic macrophytes in Mediterranean rivers. Limnologica: Ecology and Management of Inland Waters, 42(2), 95-107.

Doke, S. K., \& Dhawale, S. C. (2015). Alternatives to animal testing: A review. Saudi Pharmaceutical Journal, 23(3), 223-229.

Environment Canada. (2007). EPS 1/RM/25. Biological Test Method: Growth Inhibition Test Using a Freshwater Alga. Manual. Ontario, Canada: Environment Canada.

EPA, Environmental Protection Agency. (1992). EPA Method 9200: Nitrate. Rev 1. Test Methods for Evaluating Solid Waste, 
2021, Instituto Mexicano de Tecnología del Agua

Open Access bajo la licencia CC BY-NC-SA 4.0

(https://creativecommons.org/licenses/by-nc-sa/4.0/)

Physical/Chemical Methods, SW-846. Manual. Washington, DC, USA: Environmental Protection Agency.

EPA, Environmental Protection Agency. (2002). EPA Method 1003.0: Green Alga, Selenastrum capricornutum, Growth Test, Chronic Test. United States Environmental Protection Agency. Manual. Washington, DC, USA: Environmental Protection Agency.

Faggi, A., \& Breuste, J. (2014). La cuenca Matanza-Riachuelo: una mirada ambiental para recuperar sus riberas. Buenos Aires, Argentina: Editorial Universidad de Flores.

Ferrari, L. (2015). La ecotoxicología aplicada a la evaluación de la contaminación de los ríos: el caso del río Reconquista. Ciencia e Investigación, 65(2), 17-35.

Fire, A. (2007). Gene silencing by double-stranded RNA. Cell Death and Differentiation, 14, 6966-6984.

Franklin, N. M., Stauber, J. L., \& Lim, R. P. (2001). Development of flow cytometry-based algal bioassays for assessing toxicity of copper in natural waters. Environmental Toxicology and Chemistry, 20(1), 160-170.

González, F. (2012). Cañuelas: metropolización y disputas por los usos del suelo. Memorias. VII Jornadas de Sociología de la UNLP. 5-7 de diciembre de 2012, La Plata, Buenos Aires, Argentina.

González-Pérez, Y., Marcos-Albear, E., Pérez-Garrido, N., Marín-Sánchez, D., \& Argota-Pérez, G. (2012). Aplicación de un bioensayo 
ecotoxicológico en la evaluación de una mezcla compleja ambiental. Higiene y Sanidad Ambiental, 12(1), 839-845.

Haegerbaeumer, A., Höss, S., Ristau, K., Claus, E., Möhlenkamp, C., Heininger, P., \& Traunspurger, W. (2016). A comparative approach using ecotoxicological methods from single-species bioassays to model ecosystems. Environmental Toxicology and Chemistry, 35(12), 2987-2997.

Hitchcock, D. R., Black, M. C., \& Williams, P. L. (1997). Investigations into using the nematode Caenorhabditis elegans for municipal and industrial wastewater toxicity testing. Archives of Environmental Contamination and Toxicology, 33(3), 252-260.

Höss, S., Ahlf, W., Bergtold, M., Bluebaum-Gronau, E., Brinke, M., Donnevert, G., Menzel, R., Möhlenkamp, C., Ratte, H., Traunspurger, W., von Danwitz, B., \& Pluta, H. (2012). Interlaboratory comparison of a standardized toxicity test using the nematode Caenorhabditis elegans (ISO 10872). Environmental Toxicology and Chemistry, 31(7), 1525-1535.

Höss, S., Menzel, R., Gessler, F., Nguyen, H. T., Jehle, J., \& Traunspurger, W. (2013). Effects of insecticidal crystal proteins (Cry proteins) produced by genetically modified maize (Bt maize) on the nematode Caenorhabditis elegans. Environmental Pollution, 178, 147-151.

Hunter, D. C., \& Burritt, D. J. (2002). Improved adventitious shoot production from cotyledon explants of lettuce (Lactuca sativa L.). Scientia Horticulturae, 95(4), 269-276. 
ISO, International Organization for Standardization. (2010). ISO 10872: 2010. Water Quality - Determination of the toxic effect of sediment and soil samples on growth, fertility and reproduction of Caenorhabditis elegans (Nematoda). International Organization for Standardization. Recuperado de https://www.iso.org/standard/46253.html.

Iqbal, M. (2016). Vicia faba bioassay for environmental toxicity monitoring: A review. Chemosphere, 144, 785-802.

Khanna, N., Cressman, C. P., Tatara, C. P., \& Williams, P. L. (1997). Tolerance of the nematode Caenorhabditis elegans to $\mathrm{pH}$, salinity, and hardness in aquatic media. Archives of Environmental Contamination and Toxicology, 32(1), 110-114.

Kim, E., Jun, Y. R., Jo, H. J., Shim, S. B., \& Jung, J. (2008). Toxicity identification in metal plating effluent: Implications in establishing effluent discharge limits using bioassays in Korea. Marine Pollution Bulletin, 57(6-12), 637-644.

Leung, M., Williams, P., Benedetto, A., Au, C., Helmcke, K., Aschner, M., \& Meyer, J. (2008). Caenorhabditis elegans: An emerging model in biomedical and environmental toxicology. Toxicological Sciences, 106(1), 5-28.

Lewis, J. A., \& Fleming, J. T. (1995). Basic culture methods. In: Epstein, H. F., \& Shakes, D. C. (eds.). Methods in cell biology. Caenorhabditis elegans, modern biological analysis of an organism (pp. 4-27). San Diego, USA: Academic Press. 
Maltby, L., Arnold, D., Arts, G., Davies, J., Heimbach, F., Pickl, C., \& Poulsen, V. (2010). Aquatic macrophyte risk assessment for pesticides. Boca Raton, USA: CRC Press-SETAC Press.

Mendoza-Cantú, A., Ramírez-Romero, P., \& Pica-Granados, Y. (2007). Environmental legislation and aquatic ecotoxicology in Mexico: Past, present and future scenarios. Journal of Environmental Science and Health, Part A 42(10), 1343-1348.

Messetta, M. L., Hegoburu, C., Casas-Ruiz, J. P., Butturini, A., \& Feijoó, C. (2017). Characterization and qualitative changes in DOM chemical characteristics related to hydrologic conditions in a Pampean stream. Hydrobiologia, 803, 1-17.

Mkandawire, M., Teixeira-da-Silva, J. A., \& Dudel, E. G. (2014). The Lemna bioassay: Contemporary issues as the most standardized plant bioassay for aquatic ecotoxicology. Critical Reviews in Environmental Science and Technology, 44(2), 154-197.

Moreira-Santos, M., Soares, A. M. V. M., \& Ribeiro, R. (2004). An in situ bioassay for freshwater environments with the microalga Pseudokirchneriella subcapitata. Ecotoxicology and Environmental Safety, 59(2), 164-173.

OECD, Organization for Economic Cooperation and Development. (2006). OECD Test No. 208: Terrestrial Plant Test: Seedling Emergence and Seedling Growth Test. OECD Publishing, Paris. 
OECD, Organization for Economic Cooperation and Development. (2011). OECD Test No. 201: Freshwater Alga and Cyanobacteria, Growth Inhibition Test. Paris, France: OECD Publishing.

Olguín, H. F., Puig, A., Loez, C. R., Salibián, A., Topalián, M. L., Castañé, P. M., \& Rovedatti, M. G. (2004). An integration of water physicochemistry, algal bioassays, phytoplankton and zooplankton for ecotoxicological assessment in highly polluted lowland River. Water, Air and Soil Pollution, 155, 355-381.

Palma, P., Alvarenga, P., Palma, V., Matos, C., Fernandes, R. M., Soares, A., \& Barbosa, I. R. (2010). Evaluation of surface water quality using an ecotoxicological approach: A case study of the Alqueva Reservoir (Portugal). Environmental Science and Pollution Research, 17(3), 703-716.

Priac, A., Badot, P. M., \& Crini, G. (2017). Treated wastewater phytotoxicity assessment using Lactuca sativa: Focus on germination and root elongation test parameters. Comptes Rendus Biologies, 340(3), 188-194.

R Core Team. (2016). R: A language and environment for statistical computing. Vienna, Austria: R Foundation for Statistical Computing. Recuperado de http://www.r-project.org/

Rodríguez-Romero, A. J., Robles-Salazar, C. A, Ruíz-Picos, R. A., López, E., Sedeño-Díaz, J. E., \& Rodriguez-Dorantes, A. (2014). Índices de germinación y elongación radical de Lactuca sativa en el 
biomonitoreo de la calidad del agua del río Chalma. Revista Internacional de Contaminación Ambiental, 30(3), 307-316.

Salibián, A. (2006). Ecotoxicological assessment of the highly polluted Reconquista river of Argentina. Reviews of Environmental Contamination and Toxicology, 185, 35-65.

Samudro, G., \& Mangkoedihardjo, S. (2010). Review on BOD, COD and BOD/COD ratio: A triangle zone for toxic, biodegradable and stable levels. International Journal of Academic Research, 2, 235-239.

Schneider, C. A., Rasband, W. S., \& Eliceiri, K. W. (2012). NIH Image to ImageJ: 25 years of image analysis. Nature Methods, 9, 671-675.

Sobrero, M. C., \& Ronco, A. (2004). Capítulo 4. Ensayo de toxicidad aguda con semillas de lechuga Lactuca sativa L. En: Castillo, G. (ed.). Ensayos toxicológicos y métodos de evaluación de calidad de aguas. Estandarización, intercalibración, resultados y aplicaciones (pp. 7179). Jiutepec, México: Instituto Mexicano de Tecnología del Agua.

Solano-Padilla, A. (2007). Ensayo de toxicidad aguda al efluente de la PTAR del Municipio de Chía mediante la utilización de semillas de Lactuca sativa $L$ y propuesta para su utilización como agua de riego para hortalizas (tesis de licenciatura). Facultad de ingenieńa Ambiental y Sanitaria, Universidad de la Salle, Bogotá, Venezuela.

Stevenson, J. (2014). Ecological assessments with algae: A review and synthesis. Journal of Phycology, 50(3), 437-461. 
Strobl, R. O., \& Robillard, P. D. (2008). Network design for water quality monitoring of surface freshwaters: A review. Journal of Environmental Management, 87(4), 639-648.

Teodorović, I. (2009). Ecotoxicological research and related legislation in Serbia. Environmental Science and Pollution Research, 16(1), 123129.

Young, B. J., Riera, N. I., Beily, M. E., Bres, P. A., Crespo, D. C., \& Ronco, A. E. (2012). Toxicity of the effluent from an anaerobic bioreactor treating cereal residues on Lactuca sativa. Ecotoxicology and Environmental Safety, 76(2), 182-186.

Wang, W. (1991). Literature review on higher plants for toxicity testing. Water, Air and Soil Pollution, 59, 381-400. 